\title{
Molecular blockade of VEGFR2 in human epithelial ovarian carcinoma cells
}

\author{
Sirin Al Adham, Ifat Sher ${ }^{1}$ and Brenda L Coomber
}

\begin{abstract}
Human epithelial ovarian cancer (EOC) is the most lethal neoplasm affecting the female genital tract, and is characterized by overexpression of vascular endothelial growth factor (VEGF) and growth as ascites. Anti-VEGF strategies are currently used in EOC therapy with promising results; however, molecular targeting of specific VEGF receptors on the cancer cells themselves has not been explored to date. We previously showed that activation of a VEGF/VEGFR2 signaling loop in EOC cells supports their survival in suspension, and short-term pharmacological inhibition of this loop increased EOC cell apoptosis in vitro. In this study, we stably knocked down VEGFR2 in OVCAR-3 and SKOV-3 EOC cells using short hairpin RNA (shRNA), an RNA interference strategy that could potentially overcome chemoresistance arising with angiogenic inhibitors. Unexpectedly, we observed an induction of more aggressive cellular behavior in transfected cells, leading to increased growth in mouse xenografts, enhanced accumulation of ascites, increased VEGF and neuropilin-1 (NRP-1) expression, and decreased expression of adhesion proteins, notably cadherins and integrins. Sonic hedgehog (SHH) pathways do not seem to be involved in the upregulation of NRP-1 message in VEGFR2 knockdown cells. Supporting our mouse model, we also found a significant increase in the ratio between NRP-1 and VEGFR2 with increasing tumor grade in 80 cases of human EOC. The change in EOC behavior that we report in this study occurred independent of the angiogenic response and shows the direct effect of VEGF blockade on the cancer cells themselves. Our findings highlight the possible confounding events that may affect the usefulness of RNAi in a therapeutic setting for disrupting EOC cell survival in ascites.
\end{abstract}

Laboratory Investigation (2010) 90, 709-723; doi:10.1038/labinvest.2010.52; published online 1 March 2010

KEYWORDS: adhesion; ascites; cadherin; integrin; neuropilin-1; shRNA

Epithelial ovarian carcinoma (EOC) is the most prevalent form of ovarian cancer, accounting for nearly $90 \%$ of all ovarian tumors. ${ }^{1}$ EOC has an overall poor survival rate, primarily because the majority of patients are diagnosed at an advanced stage and most patients relapse and develop chemoresistance. ${ }^{2,3}$ The angiogenic molecule vascular endothelial growth factor (VEGF) is more highly expressed in malignant versus benign ovarian tumors and associated with tumorigenicity and cancer progression. ${ }^{3-5}$ Anti-VEGF therapies reduce tumor growth and ascites burden and enhance survival in murine models of EOC, ${ }^{6-8}$ and treatment with the VEGF antagonist bevacizumab (Avastin) prolonged survival in mice when used as maintenance therapy after a complete response to cisplatin-based chemotherapy. ${ }^{9}$ Several human phase II trials showed significant activity in EOC when bevacizumab was used as a single agent, suggesting that the blockade of VEGF signaling may prove effective in clinical disease. However, response rates were variable. For example, Cannistra $e a^{11}$ evaluated bevacizumab in a highly resistant patient population and reported a clinical response rate of approximately $16 \%$, whereas other groups report a response rate of $21 \%{ }^{10-12}$ Recent pre-clinical studies show that antiangiogenic inhibitors can cause opposing effects on tumor growth and metastasis, depending on tumor stage and treatment duration. ${ }^{13-15}$ Taken together, these findings highlight the potential for undesirable outcomes under prolonged VEGF signaling blockade in EOC.

VEGF molecules have overlapping abilities to interact with their cell surface receptors, a family of receptor tyrosine kinases of which VEGFR2 is considered the main angiogenic receptor through its mediation of the growth and permeability actions of VEGF. ${ }^{16}$ Neuropilin-1 (NRP-1) and 2 are co-receptors for VEGFR2 that help to enhance the angiogenic signal. ${ }^{17}$ Higher levels of NRP-1 expression by cancer cells 
directly correlated with increasing malignancy and oncogenesis in ovarian cancer, and suppressing NRP-1 using RNAi reduced cell growth and invasion of SKOV-3 cells in vitro. ${ }^{18}$ NRP-1 is also a receptor for L1 adhesion molecule, which might support the growth and proliferation of ovarian cancer cells in ascites and solid tumors. ${ }^{19}$ Gene silencing with RNA interference is a promising new anti-neoplastic approach through its ability to target important genes and it has been used to specifically knock down VEGF isoforms in ID8 malignant mouse epithelial ovarian cells. ${ }^{20}$

We recently showed that short-term pharmacological inhibition of VEGFR2 signaling in EOC cells reduced survival in suspension cultures in vitro, ${ }^{21}$ and this motivated us to examine the effect of long-term dampening of this signal pathway by stable reduction in the expression of VEGFR2. In this study we used the human chemoresistant EOC cell lines, OVCAR-3 and SKOV-3, to generate stable transfected clones using two different short hairpin RNA (shRNA) sequences targeting $K D R$. Contradictory to what has been reported with VEGF/VEGFR2 inhibitors and to what we expected, EOC cells with RNAi-induced VEGFR2 knockdown showed overexpression of VEGF in suspension, and grew more successfully as intrapertitoneal ascites and as subcutaneous tumors in immune-deficient mice. They also showed altered cell adhesion and adhesion molecule expression and an inverse relationship between levels of VEGFR2 and its coreceptor NRP-1. Sonic hedgehog (SHH) pathways do not seem to be involved in this upregulation of NRP-1 message in VEGFR2 knockdown cells. Supporting our mouse model, we found a significant increase in the ratio between NRP-1 and VEGFR2 expression with increasing tumor grade in 80 cases of human EOC. Our results reveal additional evidence for the interaction between VEGF pathway molecules in ovarian cancer cells, and show potential limitations of applying specific VEGFR molecular blockade in a therapeutic setting.

\section{MATERIALS AND METHODS Cell Culture}

The human epithelial ovarian cancer cell lines, NIH: OVCAR3 and SKOV3, were purchased from American Type Culture Collection (Manassas, VA, USA). Cells were grown in DME medium (Sigma-Aldrich, Oakville, ON, Canada) supplemented with $10 \%$ heat-inactivated fetal bovine serum (FBS), $50 \mu \mathrm{g} / \mathrm{ml}$ gentamicin, and $1 \mathrm{mmol} / \mathrm{l}$ sodium pyruvate, at $37^{\circ} \mathrm{C}$ in a humidified atmosphere containing $5 \% \mathrm{CO}_{2}$.

\section{Suspension Cultures and ELISA}

For survival in suspension as single cells, cells were plated on $100 \mathrm{~mm}$ dishes coated with $1 \%$ agarose (Fisher, Toronto, ON, Canada) at a very low density ( $\sim 50$ cells $/ 10 \mathrm{~cm}$ plate) in $5 \mathrm{ml}$ of growth media, and kept without disruption for up to 7 days in three independent experiments. For anchorageindependent culture of spheroids, $5 \times 10^{6}$ cells were seeded in flat-bottomed, 48-well plates previously coated with
$1 \%$ agarose and cultured for 4-5 days in DME medium supplemented with 10\% FBS. Conditioned media from suspension cultures was collected and subjected to quantification by ELISA for human-specific VEGF-A following the manufacturer's protocol (R\&D Systems, Minneapolis, MN, USA).

\section{Short-Term Inhibition of VEGFR2}

For short-term inhibition of VEGFR2 signaling, the smallmolecule tyrosine kinase inhibitor ZM323881 hydrochloride (Tocris Bioscience, Ellisville, MS, USA) was used as previously reported. ${ }^{21} \mathrm{ZM}$ inhibitor was diluted in DMSO and added in a final concentration of $5 \mathrm{nM}$; identical volumes of DMSO were added as control. The media were changed and fresh inhibitor was added every 3 days. Conditioned media samples were collected after 5 and 10 days and were used to quantify VEGF produced by the cells using VEGF ELISA as described above. Samples from at least two independent experiments were tested in triplicates or quadruplicates.

\section{VEGFR2 Transient Knockdown}

We used two different RNAi sequences: siRNAKDR1, a sequence that has shown efficient knockdown of VEGFR2 in endothelial cells in a previous report, ${ }^{22}$ and siRNAKDR5, a sequence that was designed specifically for human KDR gene (accession number NM002253). Both RNAi sequences were purchased from Dharmacon (Chicago, IL, USA). The two sequences were:

siRNA KDR1 5'-GCGGCTACCAGTCCGGATA-3'

siRNA KDR5 5'-GGAAATCTCTTGCAAGCTA-3'.

A total of 10000 OVCAR-3 cells were grown for $24 \mathrm{~h}$ on sterile round glass coverslips in a 12 -well plate in $1 \mathrm{ml}$ of complete growth media. The cells were washed with PBS, and $900 \mu \mathrm{l}$ of Opti-MEM reduced serum medium (GIBCO-BRL, Burlington, ON, Canada) was added to each well, a $100 \mu \mathrm{l}$ mixture siRNA duplex mixed with Lipofectamine-2000 (Invitrogen, Burlington, ON, Canada) was added in different concentrations, and Lipofectamine without siRNA duplexes was used as negative control. The cells were incubated for $48 \mathrm{~h}$, and coverslips were removed gently and placed on slides for immunofluorescence staining.

\section{shRNA Cloning and Transfection}

OVCAR-3 cells were initially transfected with plasmid expressing enhanced green fluorescence protein pEGFP-N1 (BD Biosciences, Mississauga, ON, Canada) as a reporter for successful stable transfection and to locate transfected cells in vivo. Stable shRNA transfections of OVCAR-3 and SKOV-3 with shRNA sequences were designed and cloned according to pSilencer 4.1-CMV hygro kit from Ambion RNA company (Austin, TX, USA). shRNA sequences were: shRNAKDR1:

Top strand: 5'-GATCCGCGGCTACCAGTCCGGATATT CAAGAGATATCCGGACTGGTAGCCGCTTA- $3^{\prime}$.

Bottom strand: 5'-AGCTTAAGCGGCTACCAGTCCGGA TATCTCTTGAATATCCGGACTGGTAGCCGCG-3’ . 
shRNAKDR5:

Top strand: 5'-GATCCGGAAATCTCTTGCAAGCTATTCA AGAGATAGCTTGCAAGAGATTTCCCAA-3'. Bottom strand: 5'-AGCTTTGGGAAATCTCTTGCAAGCTATCTCTTGAATA GCTTGCAAGAGATTTCCG-3'.

Single-stranded shRNA sequences were annealed and ligated to the CMV-driven siRNA expression vector pSilencer4.1-CMV with ampicillin and hygromycin resistance genes (Ambion), transformed to DH5a E. coli. Positive clones were selected for growth by adding $150 \mathrm{mg} / \mathrm{ml}$ ampicillin to the bacterial broth media, and the plasmids were isolated using Qiagen purification kit (Mississauga, ON, Canada), and sequenced. Plasmids were then transfected into OVCAR-3 cells using Lipofectamine 2000 reagent (Invitrogen) according to the manufacturer's protocol and stable tranfectants resistant to hygromycin (40 mg/ml OVCAR-3; $100 \mathrm{mg} / \mathrm{ml}$ SKOV-3) were selected by limited dilution cloning.

\section{Indirect Immunofluorescence}

Frozen sections were fixed in $4 \%$ paraformaldehyde for $12 \mathrm{~min}$ at room temperature and washed with PBS. For VEGFR2 detection, slides were washed three times with $0.1 \%$ Triton-X-100 solution, blocked with 2\% BSA (SigmaAldrich) and $4 \%$ normal goat serum for $30 \mathrm{~min}$, and incubated overnight at $4{ }^{\circ} \mathrm{C}$ with an anti-VEGFR2 antibody (1:100; Cell Signaling Technology, Boston MA, USA). After PBS wash, slides were incubated for $30 \mathrm{~min}$ in a 1:400 dilution of either Alexa Fluor 488 (Invitrogen) or Cy3-conjugated secondary antibody (Jackson ImmunoResearch Laboratories, West Grove, PA, USA) followed by a nuclear counter-staining with DAPI ( $4^{\prime}, 6$-diamidino-2-phenylindole $)$, and mounted in DakoCytomation Fluorescent Mounting Medium (Dako, Warrington, PA, USA).

\section{Immunohistochemistry}

Tissue samples were fixed in 10\% neutral buffered formalin, and embedded in paraffin. Sections were cut, mounted, deparaffinized, and rehydrated before immunostaining. Endogenous peroxidase was quenched by incubating the slides in $3 \% \mathrm{H}_{2} \mathrm{O}_{2}$ for $10 \mathrm{~min}$. After blocking with $4 \%$ normal goat serum the sections were incubated with the primary antibody solution (1:800 dilution for GFP; Cell Signaling Technology; 1:100 dilution of both VEGFR2 and NRP1; or 1:100 dilution of goat anti-CD31; Santa Cruz Biotechnology, Santa Cruz, CA, USA) at $4{ }^{\circ} \mathrm{C}$ overnight. After washing in PBS and incubation with biotinylated secondary antibody (1:200 goat anti-rabbit or 1:100 horse anti-goat; Vector Laboratories, Burlingame, CA, USA) for $1 \mathrm{~h}$ at room temperature, slides were rinsed and treated with R.T.U. Vectastain Elite $\mathrm{ABC}$ reagent (Vector), and the reaction product was developed by incubating slides with 3,3-diaminobenzidine (DAB) for $5 \mathrm{~min}$ followed by counterstaining with Mayer's hematoxylin solution (Sigma-Aldrich). The slides were dehydrated and mounted. Primary antibodies were replaced with PBS as negative control.

\section{Western Blotting}

Cell lysates were evaluated for protein expression using western blots of native or immunoprecipitated samples. Antibodies to the following were used: VEGFR2, p-AKT, p-ERK, p-MAPK, MAPK, p-FAK, FAK, SHH, Gli-1, E-cadherin, $\beta$-actin, and $\alpha$-tubulin (Cell Signaling Technology); VEGFR1 (Abcam, Cambridge, MA, USA); NRP-1 (Santa Cruz Biotechnology); phosphVEGFR1 (Upstate, Billerica, MA, USA); and $\beta_{3}, \beta_{1}, \alpha_{5}$ integrins, $N$-cadherin and $\beta$-catenin (BD Biosciences). POD-conjugated secondary antibody and $\mathrm{BM}$ chemiluminescence western blotting substrate was used to visualize bands.

\section{Quantitative and Semiquantitative PCR}

Total RNA was isolated from the different cell lines using Tri-pure reagent (Roche, Madison, WI, USA). Reverse transcription was performed using the SuperScript III First-Strand Synthesis System (Invitrogen), and semiquantitative PCR reactions were conducted to ensure that the PCR conditions were at the logarithmic phase of the reaction for each set of primers. Actin amplification was used as a reference gene for equal loading and the resulting PCR products were analyzed by agarose gel electrophoresis. Quantitative real-time PCR was performed with LightCycler FastStart DNA Master SYBR Green I kit, using the LightCycler 3 (Roche). The PCR conditions were as follows: $95^{\circ} \mathrm{C}$ for $10 \mathrm{~min}$, followed by 45 cycles of denaturation at $95^{\circ} \mathrm{C}$ for $10 \mathrm{~s}$, annealing at $60{ }^{\circ} \mathrm{C}$ for $10 \mathrm{~s}$, and elongation at $72{ }^{\circ} \mathrm{C}$ for $10 \mathrm{~s}$. After the end of the last cycle, the melting curve was generated by beginning fluorescence acquisition at $72{ }^{\circ} \mathrm{C}$ and taking measurements every $0.1{ }^{\circ} \mathrm{C}$ until $95^{\circ} \mathrm{C}$ was reached. Samples were run in triplicate and the experiment was repeated twice with two different cDNA samples generated from two RNA isolations. The relative fold change $2-\Delta \Delta \mathrm{CT}$ method was used to determine the relative quantitative gene expression compared with $\beta$-actin. The sequence of primers used were NRP- $1:^{23}$

HNRP-F: $5^{\prime}$-GCACGTGATTGTCATGTTCC- $3^{\prime}$.

HNRP-R:5'-GGTGGATGAATGTGATGACG-3'.

And the primers used for $\beta$-actin were:

HBETA-ACTINF 5'-AAGATCAAGATCATTGCTCCTC-3'. HBETA-ACTINR 5'-CAACTAAGTCATAGTCCGCC- ${ }^{\prime}$.

\section{In Vivo Experiments}

All animal studies were performed according to the guidelines of the Canadian Council for Animal Care (CACC) and supervised by the University of Guelph local animal care committee. Female RAG1-null mice ${ }^{24}$ were inoculated intraperitoneally with $1 \times 10^{7}$ OVCAR-3 shRNA cells. After 90 days, the mice were killed, and the ascites fluid and suspended cells were collected for further analysis. $5 \times 10^{6}$ cells were injected subcutaneously into additional female RAG1-null mice, and the tumors measured twice weekly. Animals were killed by $\mathrm{CO}_{2}$ asphyxia and cervical dislocation and tissues were collected for further analysis. 


\section{Ovarian Cancer Tissue Microarray and Immunostaining} Tissue microarray slides (US Biomax, Rockville, MD, USA) had 80 cores, (single core per case), including 63 cases of serous papillary cystadenocarcinoma, 13 mucous papillary cystadenocarcinoma, 3 endometrioid adenocarcinoma, and 1 clear cell carcinoma. The slides were de-paraffinized and IHC staining with VEGFR2 and NRP-1 was performed as described above. A score from 1 to 10 was assigned in a blinded manner to describe the intensity of staining of the epithelial cancer cells in each core, and the ratio between NRP-1 score and VEGFR2 score calculated for each tissue core. Cells and tissues were immunostained according to standard protocols using the following primary antibodies from Cell Signaling Technology: anti-GFP; anti-VEGFR2, and anti-NRP-1, followed by fluorochrome- or enzyme-labeled secondary antibodies.

\section{AlamarBlue Proliferation Assay}

Cell proliferation was determined using alamarBlue Assay (BioSource Invitrogen), following the manufacturers' protocol. In brief, $1.5-3 \times 10^{4}$ cells were seeded in 96-well plates in normal growth medium. After $24 \mathrm{~h}$, cells were washed twice with DMEM, and then $100 \mu \mathrm{l}$ serum-free DME medium was added to each well. After $24 \mathrm{~h}$, alamarBlue reagent was added to each well in a final concentration of $10 \%$. After incubation, the absorbance at $570 \mathrm{~nm}$ and $630 \mathrm{~nm}$ was determined, and alamarBlue reduction was calculated based on manufacturer's instructions. Each experiment was repeated at least twice in quadruplicates.

\section{Statistical Analysis}

Statistically significant differences were determined by two-tailed unpaired Student's $t$-test and one-way ANOVA and were defined as $P<0.05$. All experiments were repeated independently at least three times.

\section{RESULTS}

\section{Inverse Relationship Between VEGFR2 Expression and} NRP-1 in EOC Cells

siRNA duplexes targeting VEGFR2 knocked down protein levels in transient transfection (Figure 1a). Stable shRNAtransfected clones (five per construct) were screened for VEGFR2 expression using western blot. All shRNAKDR1 clones were effective in silencing the expression of $K D R$, whereas some shRNAKDR5 clones showed less knockdown efficacy when compared with controls (Figure 1b). We consistently used clone shRNAKDR1-1 (95\% VEGFR2 knockdown) and clone shRNAKDR5-3 (50\% VEGFR2 knockdown) to evaluate the effect of different levels of VEGFR2 on cell function. The VEGFR2 co-receptor NRP-1 was weakly expressed in OVCAR-3 cells, but was upregulated (mRNA and protein) in shRNAKDR clones, at a level inversely proportional to the VEGFR2 knockdown (Figure 1c and d). NRP-2 was also expressed by OVCAR-3 cells, but levels did not alter with VEGFR2 knockdown (not shown).

\section{The Consequences of VEGFR2 Knockdown on Downstream Signaling Proteins}

Throughout this study we used control cells containing shRNA targeting GAPDH or the scrambled sequence to test for off-target effects upon VEGFR2 reduction by shRNA, and we found no change in VEGFR1 or in any other examined protein in both cell lines. shRNA VEGFR2 knockdown had no effect on VEGFR1 protein levels, but it reduced the levels of VEGFR1 phosphorylation (Figure 2a). VEGFR2 knockdown with transient siRNA transfection is reported to not influence the abundance of VEGFR1 in normal bovine aortic endothelial cells. ${ }^{25}$ VEGFR3 expression at the protein level was weak in the parental cells, and did not increase with VEGFR2 knockdown (not shown). We found a slight alteration in phosphorylation of protein kinase B (AKT) and focal adhesion kinase (FAK), but no change in phosphorylated mitogen-activated protein kinase (MAPK) or externally regulated kinase (ERK) levels upon VEGFR2 knockdown in these cells (Figure 2b). This is consistent with previous reports that the AKT and MAPK pathways are constitutively activated in OVCAR-3 cells.

\section{Neuropilin-1 Increase in the shRNAKDR Cells is Not Related to SHH Pathway}

In an attempt to delineate the molecular pathway involved in NRP-1 upregulation we examined the SHH pathway, shown to be activated in renal carcinoma and EOC, as NRP-1 is a known SHH gene target in these cells. ${ }^{26}$ We observed that although SHH protein was not affected by VEGFR2 levels, its downstream transcriptional factor, glioma-associated antigen-1 (Gli-1), was greatly reduced upon knockdown of VEGR2 (Figure 2c). These results suggest that transcription factors other than Gli-1 are behind the changes in NRP-1 levels that we observe, which opens new areas of investigation into the relationship between Gli-1 and the VEGF signaling pathway.

\section{Vegfr2 Knockdown Affects EOC Growth and Survival}

We noticed that shRNAKDR1 and shRNAKDR5 cells showed delayed/reduced attachment to cell culture dishes when compared with shRNAGAPDH cells (Figure 3a). There were no differences in apoptosis (as detected by flow cytometry) between VEGFR2-deficient cells grown as monolayer or in suspension for $48 \mathrm{~h}$ over control-transfected cells (Supplementary Material). However, shRNAKDR1 cells showed enhanced survival in clusters during long-term culture in suspension, whereas shRNAKDR5 showed less survival and shRNAGAPDH cells could not survive prolonged loss of adhesion (Figure $3 \mathrm{~b}$ ). This suggests modification of cell-cell and/or cell-matrix adhesion in these knockdown cells. We thus examined the expression levels of adhesion proteins known to be expressed by OVCAR-3 cells ${ }^{11}$ and found an inverse relationship between the levels of VEGFR2 and $\alpha_{5}, \beta_{1}$, and $\beta_{3}$ integrin (Figure $4 \mathrm{a}$ and $\mathrm{b}$ ). There was also an extensive reduction in $\mathrm{N}$-cadherin and a smaller decrease in E-cadherin 

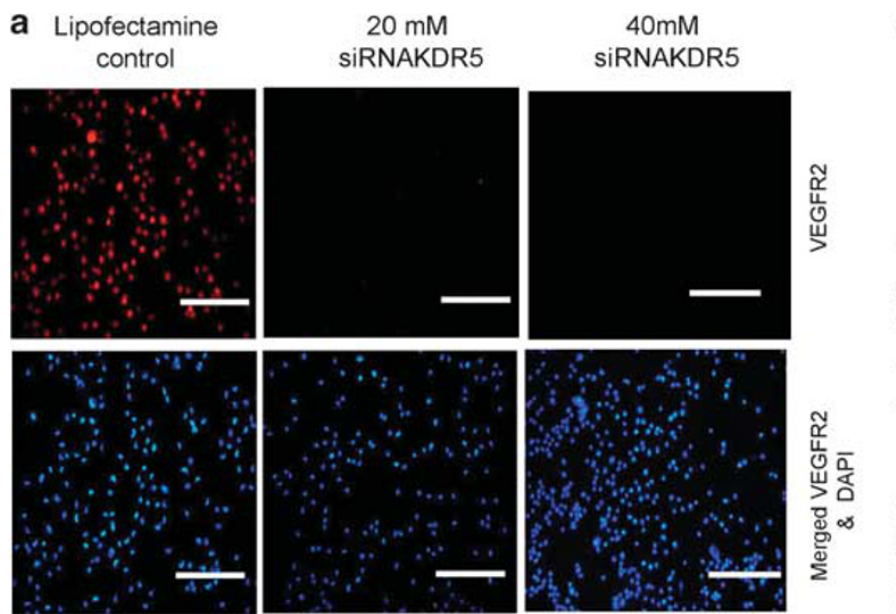

b
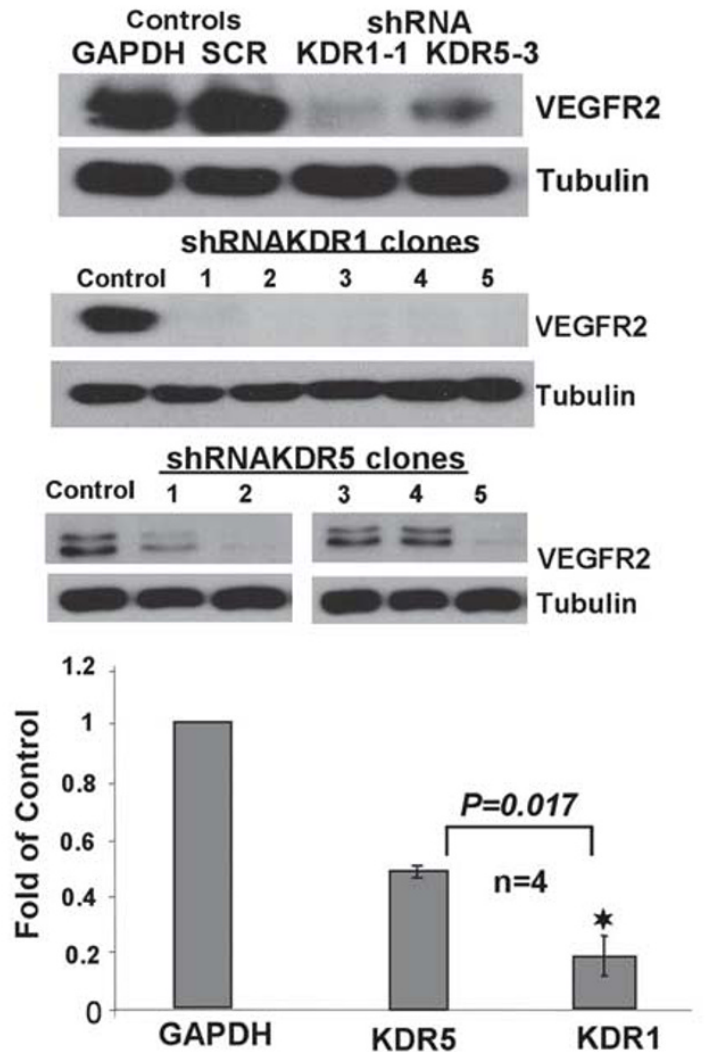

C

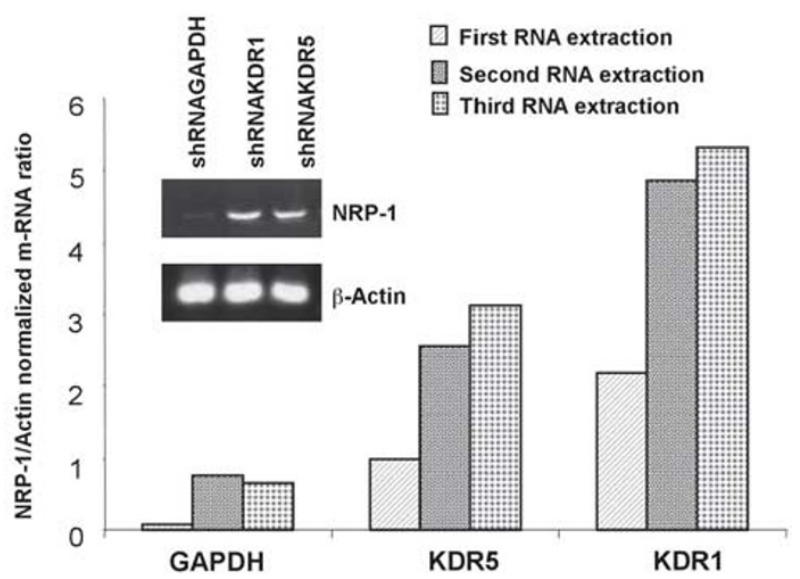

d
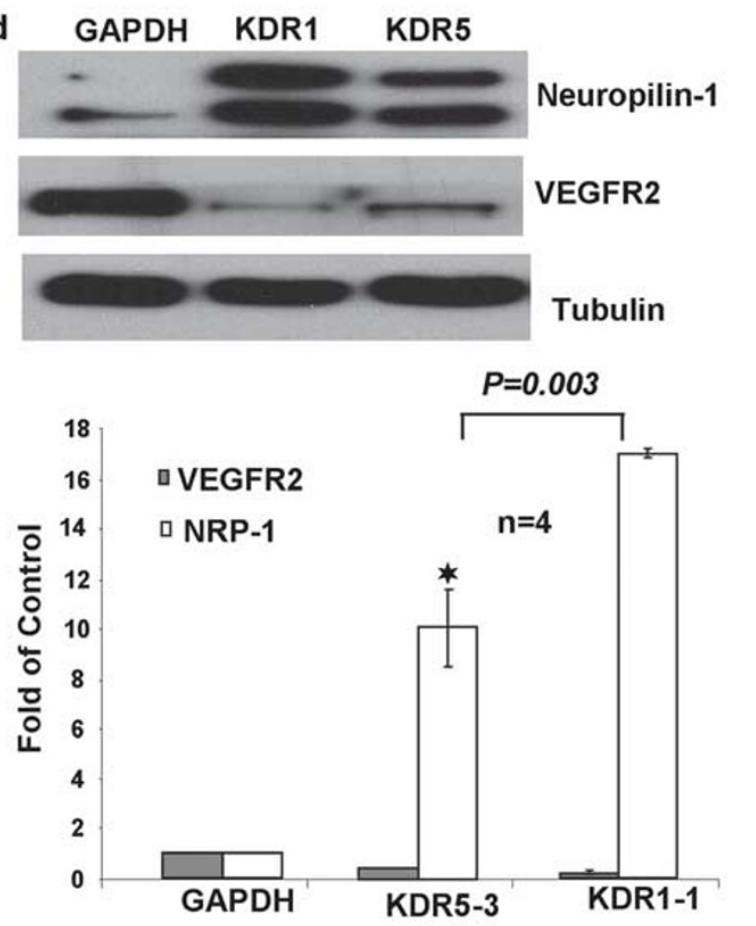

Figure 1 VEGFR2 knockdown and its consequences. (a) Immunofluorescence staining of OVCAR-3 cells transiently transfected with 21 nucleotide siRNAKDR, scale bars $=100 \mu \mathrm{m}$. (b) Upper western blot shows stable knockdown of VEGFR2 in OVCAR-3/GFP cells transfected with stable shRNA against two KDR sequences (KDR1 and KDR5) and both controls (GAPDH and scrambled SRC). Middle and lower panels: western blots showing VEGFR2 levels in five clones from each shRNA construct. Graph shows mean (s.e.m.) for densitometry readings from four different independent blots from clone 3 of shRNAKDR5 and clone 1 of shRNAKDR1. These clones were used for the subsequent experiments. (c) Ethidium bromide-stained agarose gel of semiquantitative RT-PCR reveals barely detectable levels of NRP-1 in parent OVCAR-3 cells, and enhanced levels in both KDR-transfected shRNA cells. Graph of quantitative RT-PCR confirms that shRNAKDR cells express increased levels of NRP-1 compared with GAPDH control. (d) Western blot showing that NRP-1 protein expression levels are higher in shRNAKDR knockdown OVCAR-3 cells and are inversely proportional to the extent of VEGFR2 knockdown compared with GAPDH control. The graph shows the inverse relationship between the expression of VEGFR2 and NRP-1; results are the mean \pm s.e.m. of densitometry readings representing the knockdown of VEGFR2/NRP-1 from three different blots.

protein upon VEGFR2 knockdown, but no detectable changes in the levels of $\beta$-catenin (Figure $4 \mathrm{a}$ and $\mathrm{b}$ ). Another EOC cell line, SKOV-3, subjected to identical VEGFR2 shRNA transfection revealed similar patterns of knockdown and changes in adhesion proteins and NRP-1 gene expression observed in OVCAR-3 cells (Figure 5a-d). 


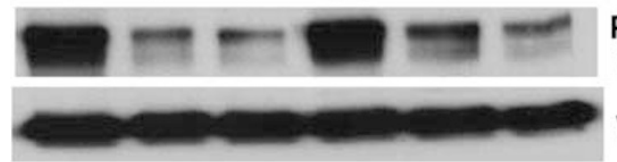

PhosphoVEGFR1

VEGFR1

\section{b}

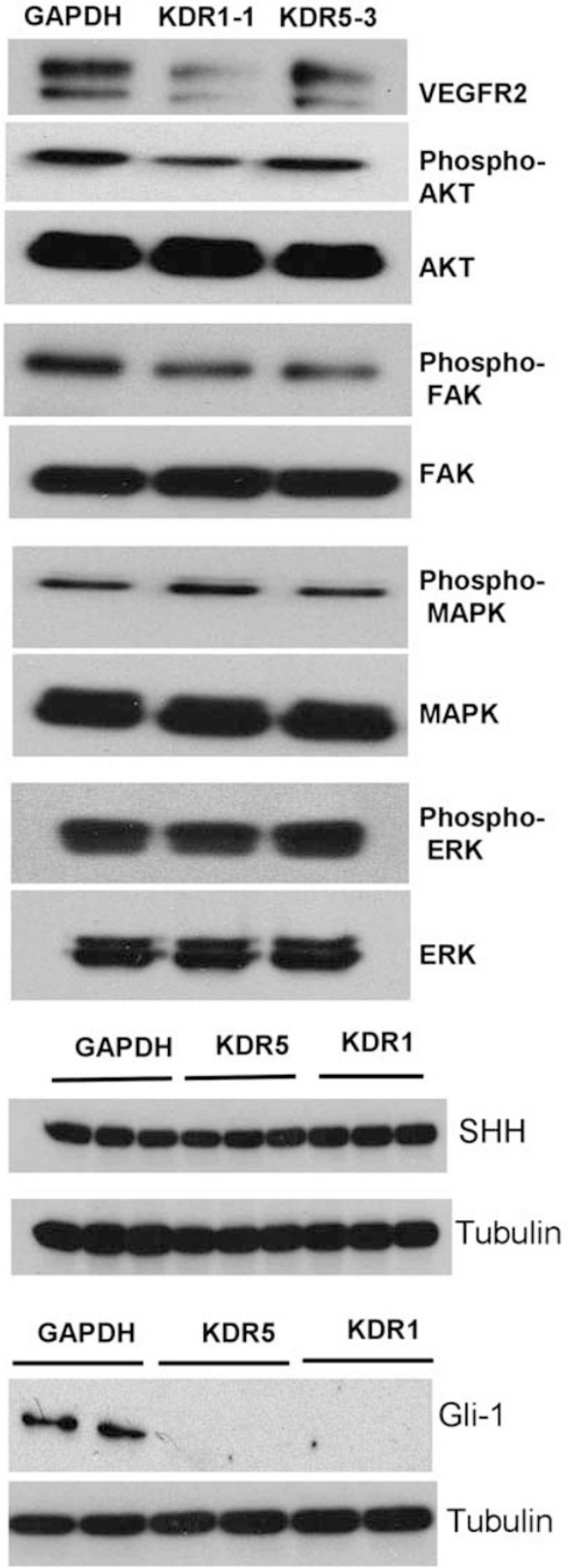

VEGF Production in VEGFR2 Knockdown Cells and the Influence of Knockdown on Cell Proliferation

As stable reduction in VEGFR2 did not result in the expected enhanced anoikis in these EOC cells when grown in suspension, we aimed to see whether this change led to altered VEGF production. There were no significant changes in VEGF secretion for cells growing in adhesion, whereas cells lacking VEGFR2 growing in single-cell suspension and as spheroids secreted significantly more VEGF than control cells (Figure 6a). Short-term pharmacological blockade of VEGFR2 signaling had the opposite effect on VEGF production (Figure $6 \mathrm{~b}$ ). shRNAKDR1 cells also showed a significant increase in proliferation when compared with other shRNA clones (Figure 6c).

\section{Vegfr2 Knockdown Enhanced EOC Intraperitoneal Implantation and Ascites Growth}

Mice implanted intraperitoneally with OVCAR-3 cells were killed after 90 days and ascites fluid and cells collected. Approximately $800 \mu \mathrm{l} /$ mouse was collected from shRNAKDR1 cell-injected mice, $500 \mu \mathrm{l} /$ mouse from shRNAKDR5 cellinjected mice, and $300 \mu \mathrm{l} /$ mouse from shRNAGAPDH cellinjected mice; in all cases, clusters of viable EOC cells with no evidence of apoptotic or necrotic cells were obtained from each ascites (Figure 6d). Lysates of cells from ascites showed the stability of the VEGFR2 knockdown (Figure 6d). We found that ascites from shRNAKDR1 cell-injected mice contained 3.6-fold more VEGF compared with that produced by shRNAKDR5 and shRNAGAPDH cells; lysates of recovered cells had similar VEGF levels to supernatant, supporting the concept that the injected OVCAR-3 cells were the main source of the enhanced VEGF produced in the ascitic fluid (Figure 6e). Immunostaining with anti-GFP (to localize transfected OVCAR-3 cells) showed cancer cells surrounding the ovary, located beneath the ovarian bursa, and infiltrating the oviduct in ascites-bearing mice (Figure 7a). Mice injected with VEGFR2 knockdown clones showed more extensive sub-bursal infiltration and growth than mice injected with control shRNAGAPDH-transfected OVCAR-3 (Figure 7a). These findings suggest that KDR knockdown

Figure 2 Changes in the expression of downstream signaling proteins and Gli-1 transcriptional factor upon KDR blockade. (a) Western blot showing expression levels and phosphorylation status of VEGFR1. VEGFR2 knockdown produced no change in VEGFR1 levels but concomitant decreases in its phosphorylation when compared with shRNAGAPDH controls. Two clones of each transfection are shown. (b) Western blot showing that VEGFR2 knockdown reduced levels of phosphorylated AKT and FAK, but did not change levels of phosphorylated ERK or phosphorylated MAPK. (c) Upper panel: western blot showing no change in $\mathrm{SHH}$ protein expression in three clones of each KDR knockdown and control cells. The lower panel of western blot for Gli-1 transcription factor shows downregulation in two different clones of each shRNA transfection without any change in the control transfected shRNAGAPDH cells. 
a
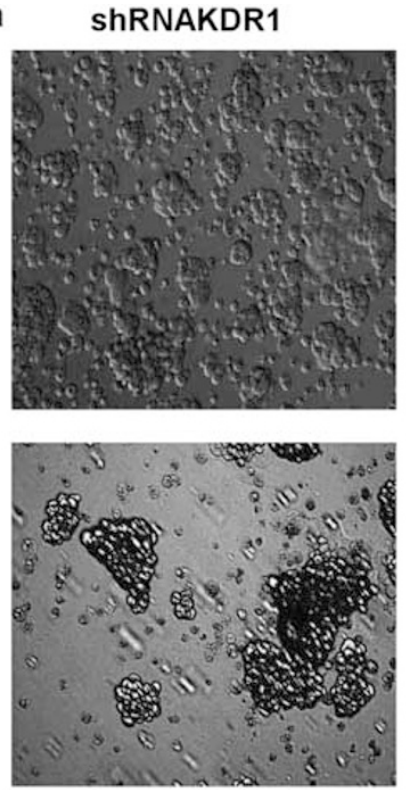

b
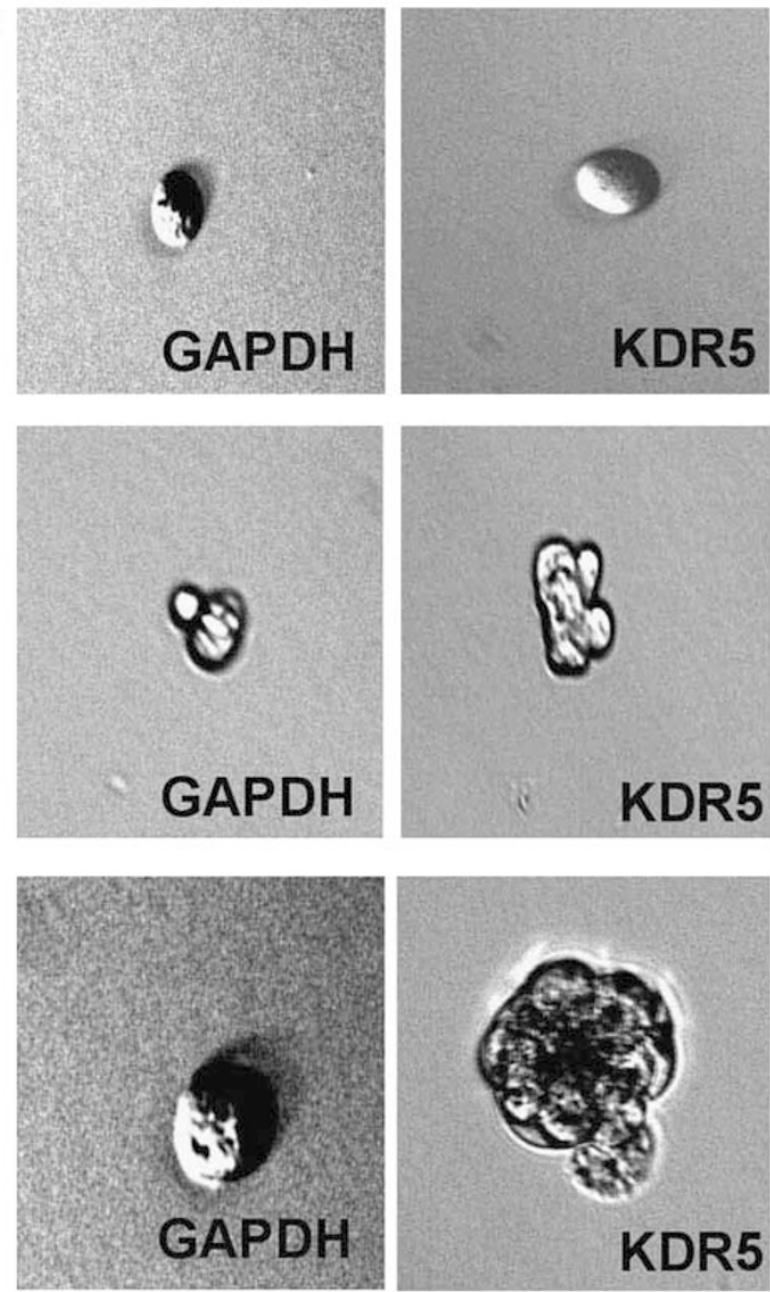

ShRNAGAPDH
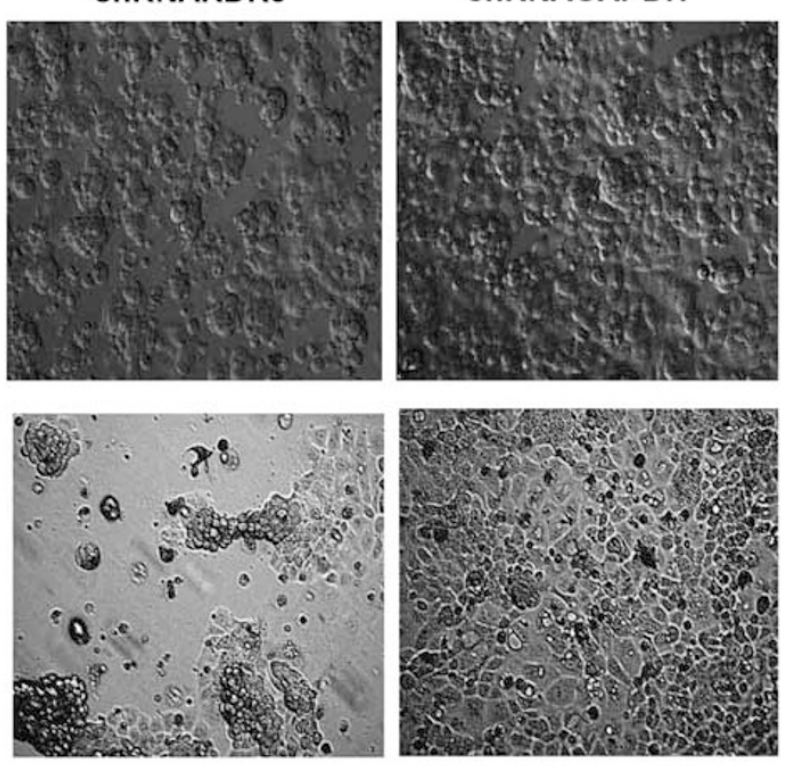

\section{5
$\frac{5}{n}$
$\frac{2}{0}$
$\frac{0}{5}$
क}

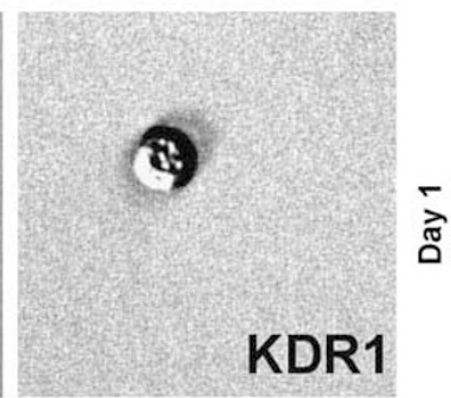

ลั

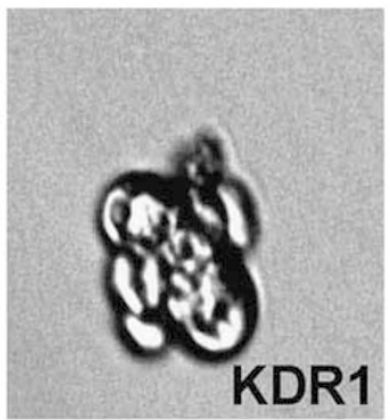

$\stackrel{m}{\text { กั }}$

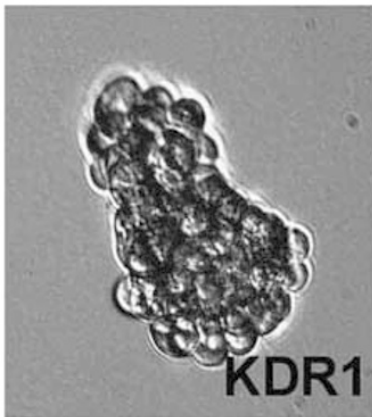

กั๊

Figure 3 Change in adhesion upon the loss of VEGFR2. (a) Phase-contrast images of transfected OVCAR-3 cells growing as monolayers in adhesive plates and in flat-bottom suspension plates. Images were captured $48 \mathrm{~h}$ after cell passage. (b) Single cells growing under suspension conditions for up to 7 days. 


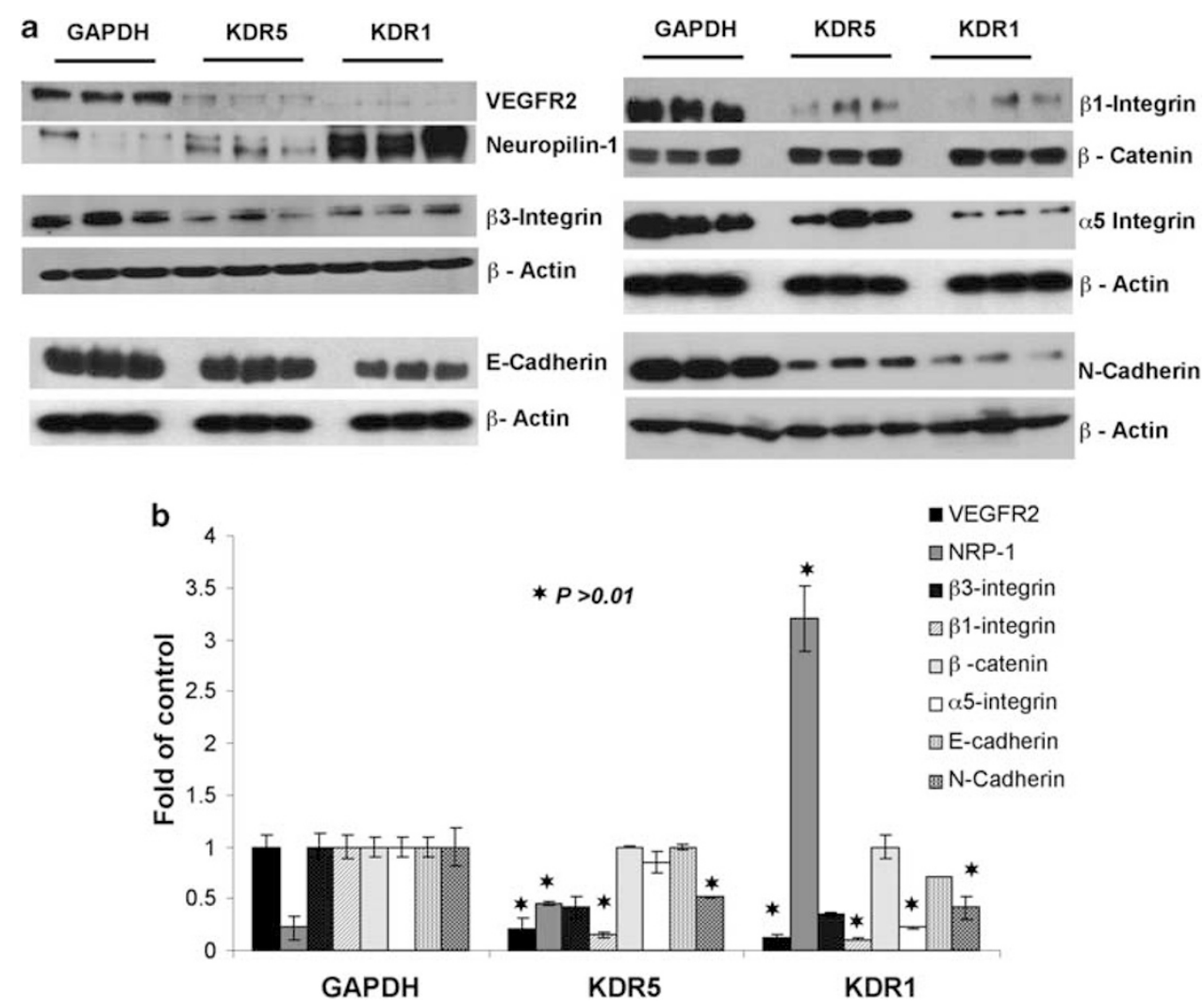

Figure 4 Quantification of adhesion protein changes upon VEGFR2 knockdown. (a) Western blots showing that knockdown of VEGFR2 in OVCAR-3 cells leads to increased NRP-1 protein and concomitant decreased expression of cell-matrix adhesion $\left(\beta_{3}, \beta_{1}\right.$, and $\alpha_{5}$ integrins) and cell-cell adhesion (E-cadherin and N-cadherin) proteins compared with GAPDH RNAi cells. (b) Densitometry readings of three independent experiments detecting the expression of the eight proteins in three clones for each construct. Results are shown as mean \pm s.e.m. $(n=3)$. Asterisks indicate significantly different protein levels from GAPDH control cells $(P \leq 0.05)$.

enhances ascites production and increases the ability of EOC cells to seed the reproductive tract in these mice.

\section{VEGFR2 Knockdown Enhanced EOC Subcutaneous Implantation and Tumor Growth}

When grown as subcutaneous xenografts, OVCAR-3 shRNA clones were characterized by fluid-filled cystic tumors. shRNAKDR1 cells produced significantly larger tumors than shRNAGAPDH cells, whereas tumors produced by shRNAKDR5 cells were intermediate in their growth rate (Figure 7b). Blood vessels density, as assessed by CD31-positive vessels, was low and did not differ between tumor type (mean \pm s.d. $/ \mathrm{mm}^{2}$; shRNAGAPDH tumor: 6.29 ; shRNAKDR5 tumors: $5.54 \pm 3.23$; and shRNAKDR1 tumors: $5.75 \pm 4.3$ ). Immunostaining for NRP- 1 and VEGFR2 confirmed that the knockdown phenotype of injected cells was still present in xenograft tumors in vivo. High NRP-1 nuclear and cytoplasmic staining was observed in shRNAKDR1 tumors, with no detectable VEGFR2 staining. Intermediate nuclear and cytoplasmic NRP-1, with nuclear VEGFR2 staining was observed in the shRNAKDR5 tumors, and low cytoplasmic NRP-1 staining combined with robust nuclear and cyto- plasmic VEGFR2 staining was observed in the control shRNAGAPDH xenografts (Figure 8a).

\section{Ratio of NRP-1:VEGFR2 Levels Increased with Tumor Grade in Human EOC}

We found that the ratio between NRP-1 and VEGFR2 staining increased with tumor grade in 80 clinical EOC specimens, and that grade III tumors had significantly higher NRP-1:VEGFR2 ratios than grade I tumors (Figure 8b), suggesting that higher NRP-1 expression is directly related to malignancy in our VEGFR2 knockdown OVCAR-3 cells. To the best of our knowledge, this study is the first to show a correlation between NRP-1:VEGFR2 ratio and human EOC tumor grade. Using the same semiquantitative scoring system on OVCAR-3, subcutaneous xenografts yielded NRP1:VEGFR2 ratios of 0.33 (GAPDH cells; $N=1$ ), 1.25 (KDR5 cells; $N=5)$, and 3.6 (KDR1 cells; $N=5)$.

\section{DISCUSSION}

Because of the importance of angiogenesis in tumor progression, several therapeutic strategies have been developed to block VEGF signaling; however, the molecular approach of targeting expression of specific VEGF receptors in cancer cells 
a
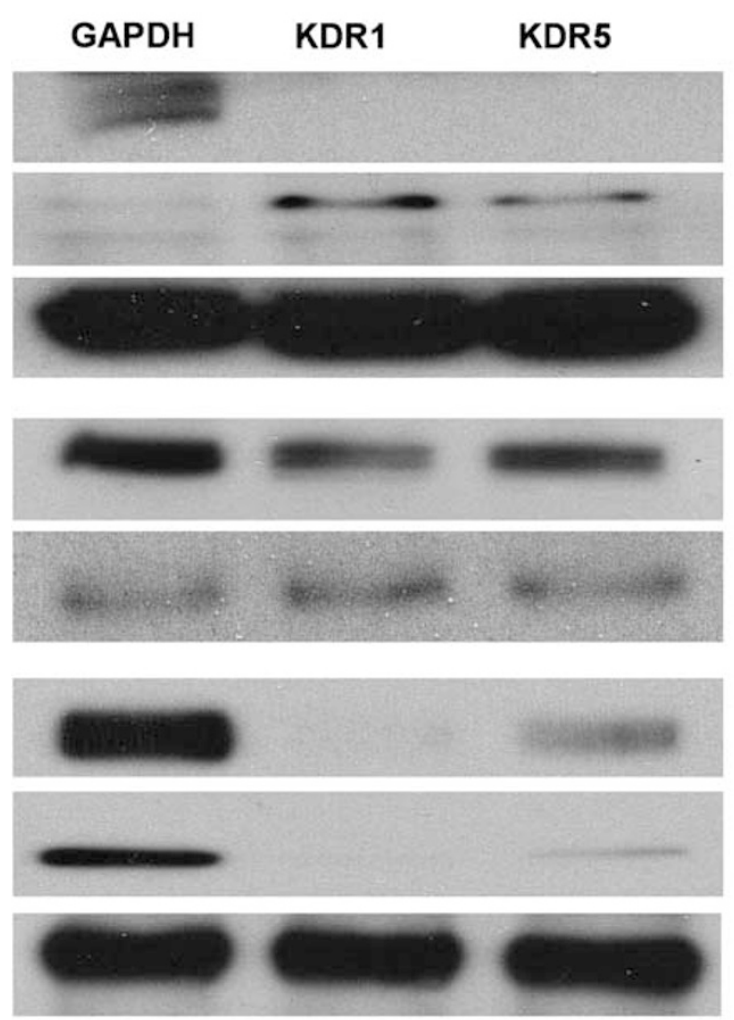

\section{P. VEGFR1}

VEGFR1

b

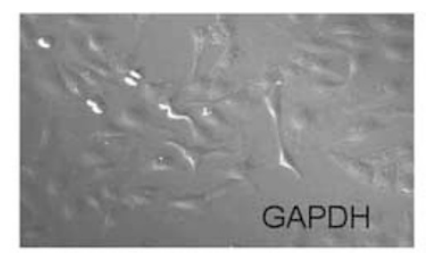

Neuropilin-1

Tubulin

VEGR1

$\alpha 5$ Integrin
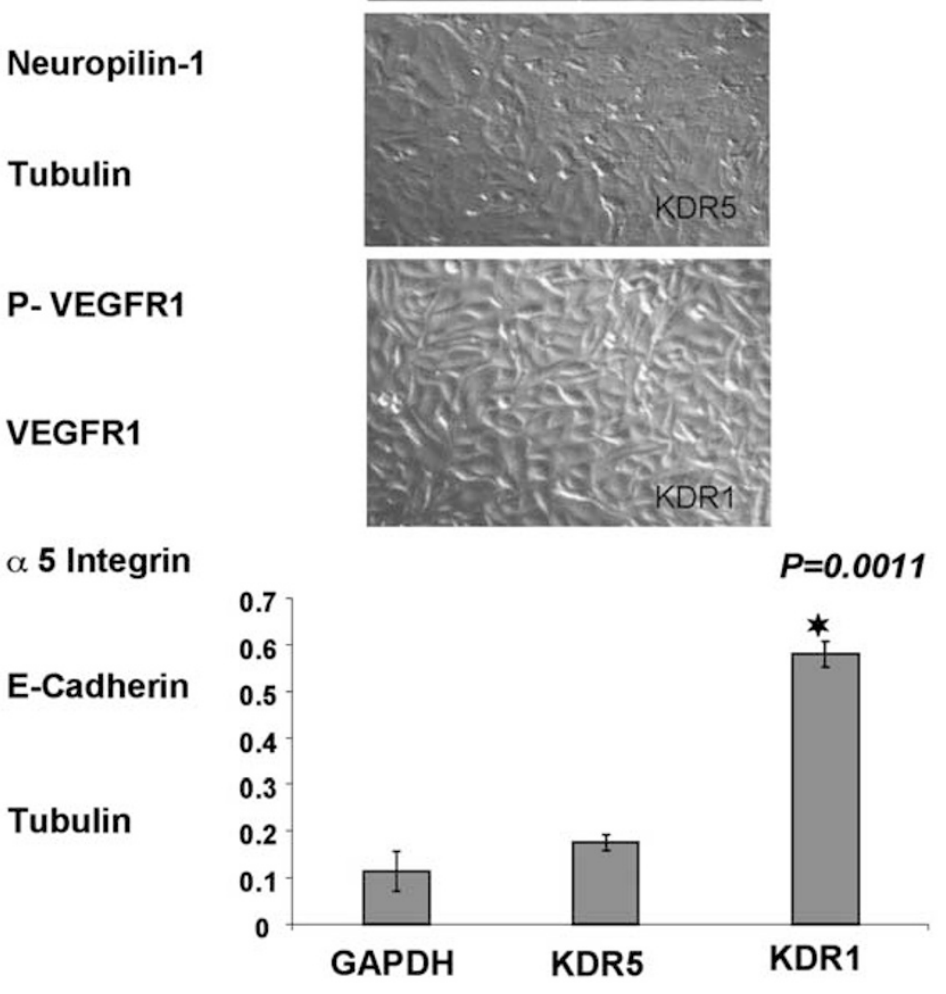

C
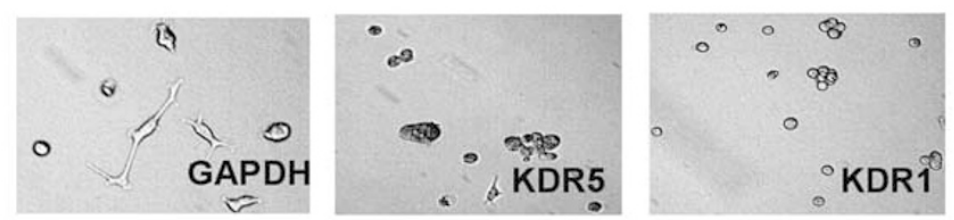

d
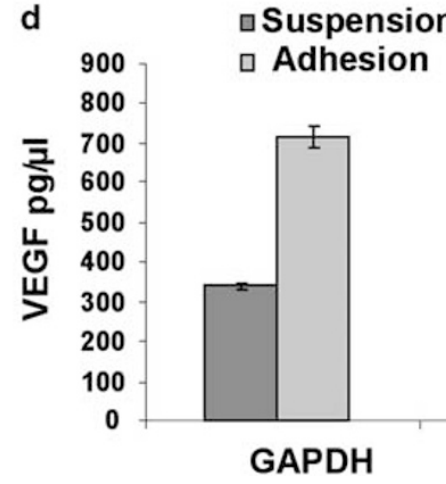

$P=0.0144$

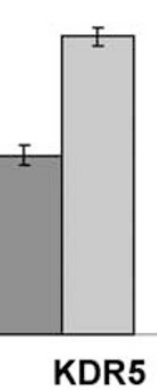

\section{$P=0.0144$}

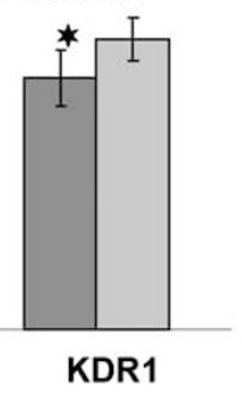

Figure 5 shRNA knockdown of VEGFR2/KDR in SKOV-3 EOC cell line has the same effect on cell proliferation and gene expression observed in OVCAR-3 cells. (a) Western blots show increased NRP-1, decrease in p-VEGFR1, no change in native VEGFR1, and decrease in both $\alpha_{5}$ integrin and E-cadherin in KDR knockdown cells. (b) Phase-contrast images of transfected SKOV-3, grown in monolayer on adhesive plates for $24 \mathrm{~h}$ after passage, shows the enhanced proliferation in KDR knockdown clones. SKOV-3 shRNAKDR1 cells show the highest proliferation and this was confirmed by alamarblue assay data from three independent replicates (mean \pm s.e.m.). (c) Phase-contrast images of SKOV-3 cells grown in low density over $1 \%$ agarose (non-adhesive surface). shRNAGAPDH control cells are able to both attach and spread on agarose whereas adhesion is reduced in shRNAKDR5 and lost in shRNAKDR1. (d) Graph of VEGF ELISA (mean \pm s.e.m.) shows higher VEGF production by SKOV-3 shRNAKDR1 in suspension and not in adhesion compared with shRNAKDR5 and ShRNAGAPDH. 

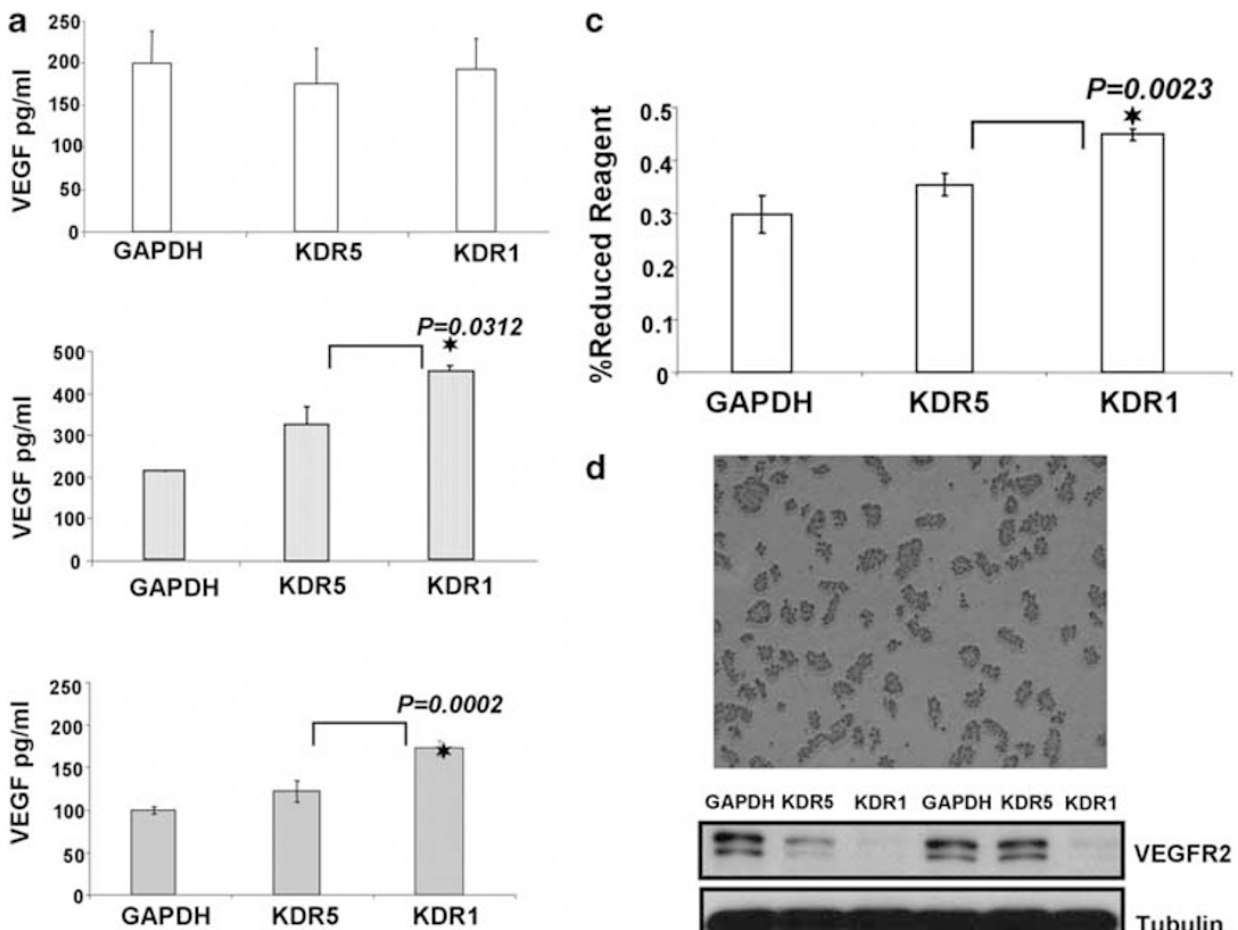

d

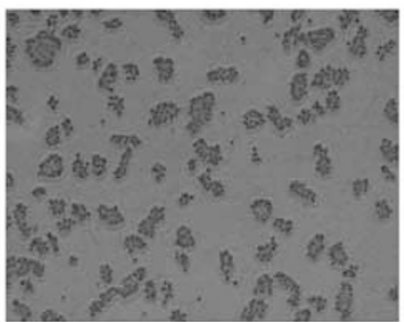

GAPDH KDR5 KDR1 GAPDH KDR5 KDR1
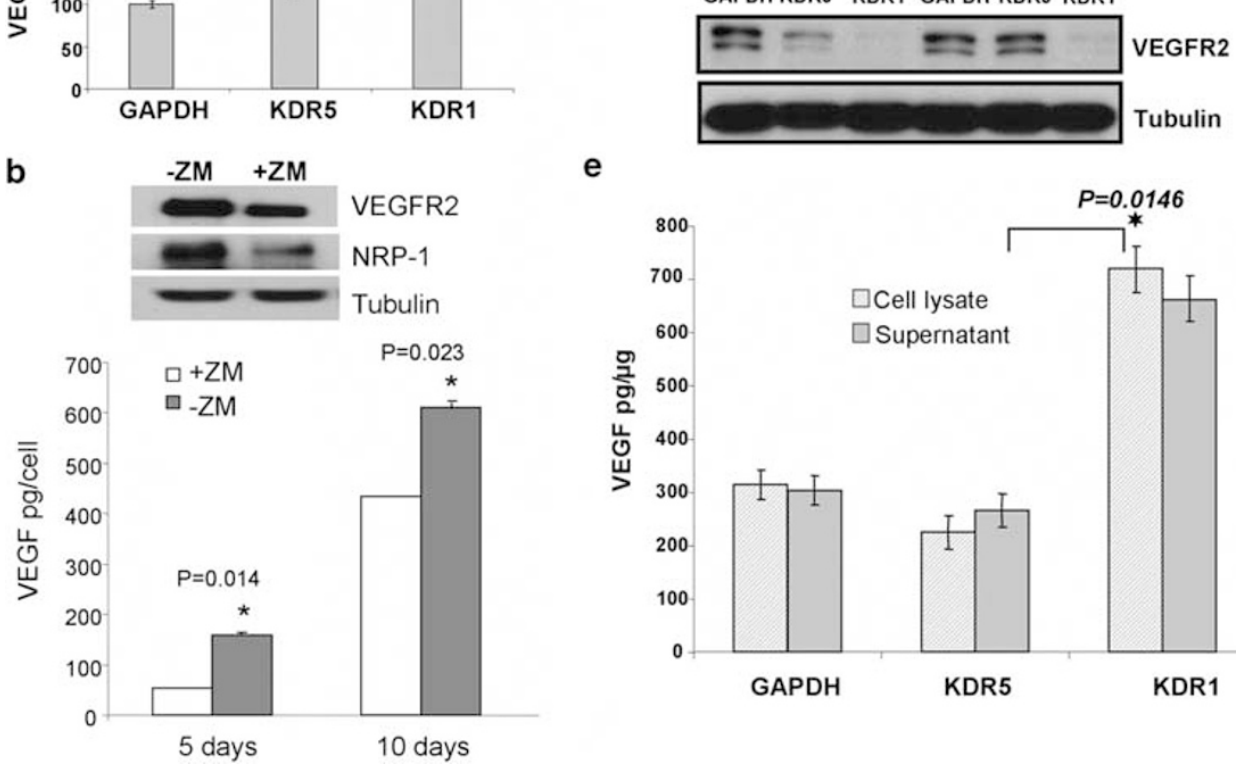

e

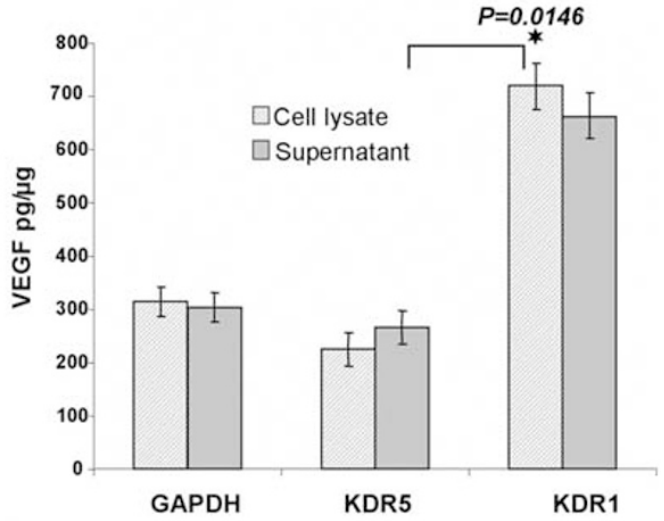

Figure 6 Increased VEGF-A production in suspension conditions by VEGFR2 OVCAR-3 knockdown cells. (a) ELISA for VEGF-A (mean \pm s.e.m.) detected no change in the amount of VEGF produced by the three OVCAR-3-transfected constructs growing in adhesive monolayer culture. The middle graph shows a significant increase in the production of VEGF-A by shRNAKDR1 clones growing in suspension and the bottom graph shows a significant increase in VEGF-A production by spheroids formed from shRNAKDR1 cells compared with shRNAKDR5 and shKDRGAPDH. (b) Short-term blockade of VEGFR2 signaling in OVCAR-3 cells with pharmacological inhibitor ZM323881 lead to reduced expression of VEGFR2, NRP-1, and VEGF. (c) Proliferation assay using alamarBlue (mean \pm s.e.m.) shows significant cell growth in shRNAKDR1 cells compared with other clones. (d) Upper panel shows ascites (OVCAR-3 cells) collected from the intraperitoneal cavity of mice; bottom panel shows western blot of collected cells, showing the stability of VEGFR2 knockdown in the recovered ascites cells. (e) ELISA results (mean \pm s.e.m.) showing higher VEGF-A production in shRNAKDR1 ascites supernatant and lysed cells recovered from intraperitoneal cavities of injected mice, compared with samples from other stable lines.

Figure 7 Effect of KDR knockdown on the malignancy of OVCAR-3 cells in vivo. (a) Adjacent sections of ovaries stained with H\&E and immunostained for GFP to identify injected EOC cells. shRNAGAPDH cells showed modest colonization of ovary bursal space whereas shRNAKDR5 and shRNAKDR1 cells showed extensive colonization of ovarian bursal space (asterisks). Occasionally, injected EOC cells also infiltrated the oviduct of shRNAKDR1-injected mice. These observations were consistent in all five mice that were injected per cell type. Reproductive tracts from uninjected mice showed no evidence of cellular infiltration or GFP staining. Scale bar $=500 \mu \mathrm{m}$. (b) Tumor growth curves for EOC subcutaneous xenografts, graph showing mean \pm s.e.m. During the 12 weeks of the trial, all shRNAKDR-injected mice grew tumors ( $N=5$ per group) and tumors from cells with the most extensive KDR knockdown (shRNAKDR1) grew significantly larger than tumors generated from shRNAKDR5. In contrast, when shRNAGAPDH control cells were injected ( $N=5)$, only one slowgrowing tumor formed. Inserts are representative images of the subcutaneous xenografts in situ before dissection. 

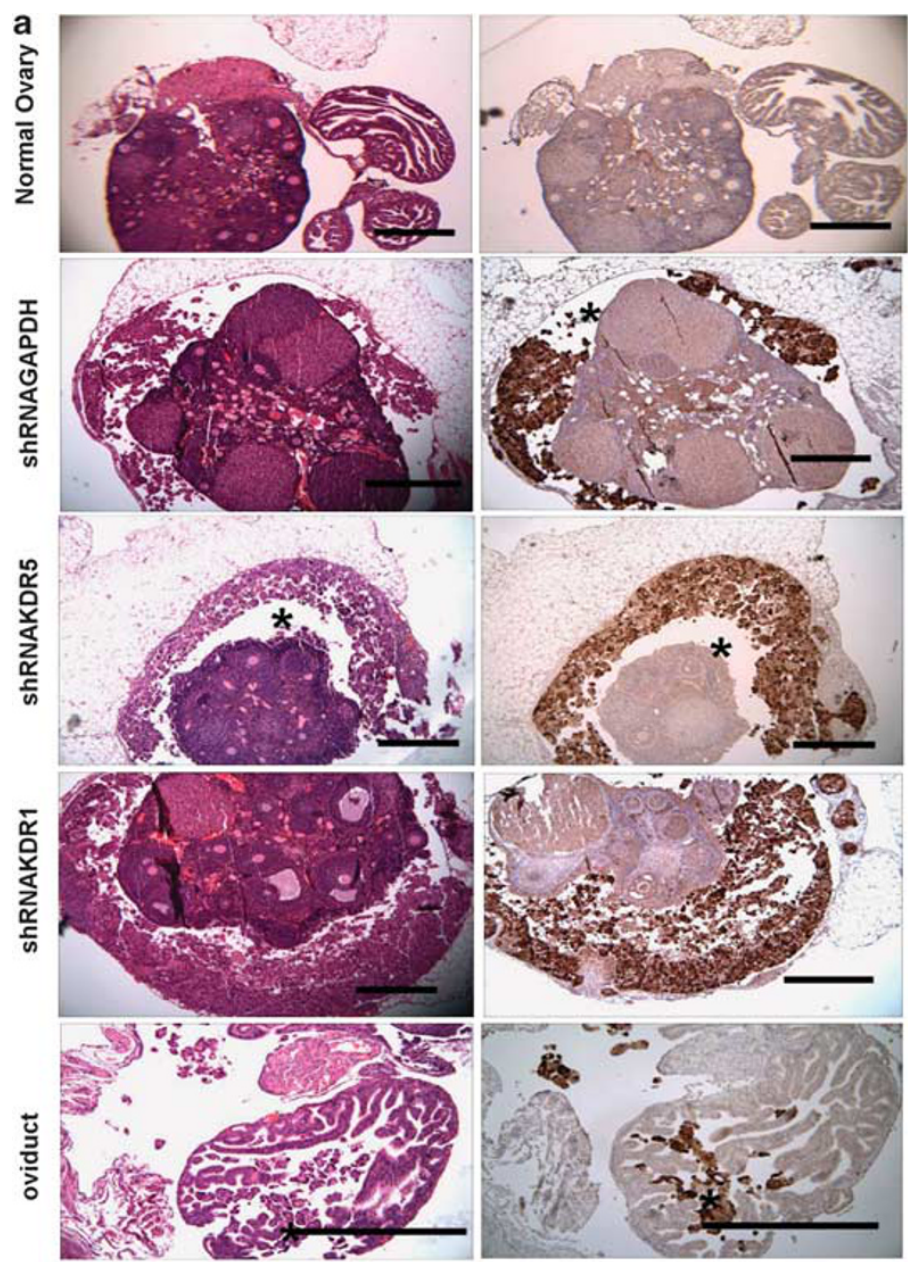

b

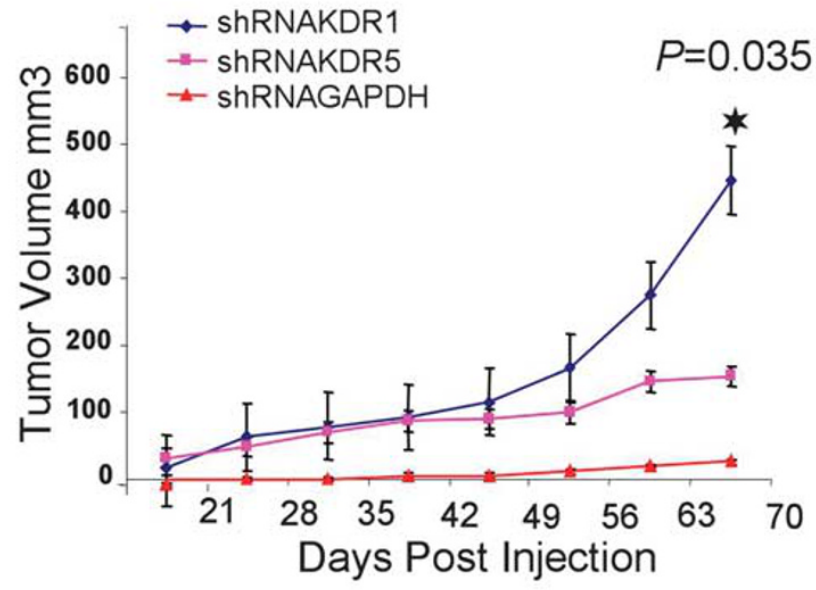

shRNAGAPDH

ShRNAKDR5

ShRNAKDR1
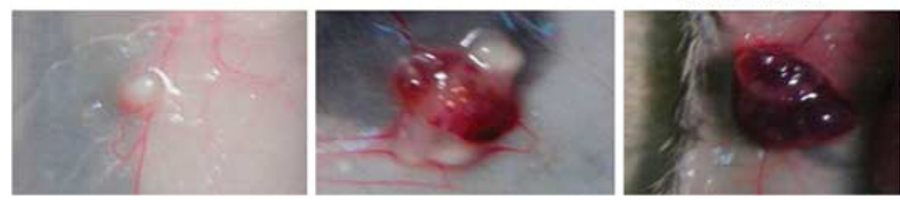
a
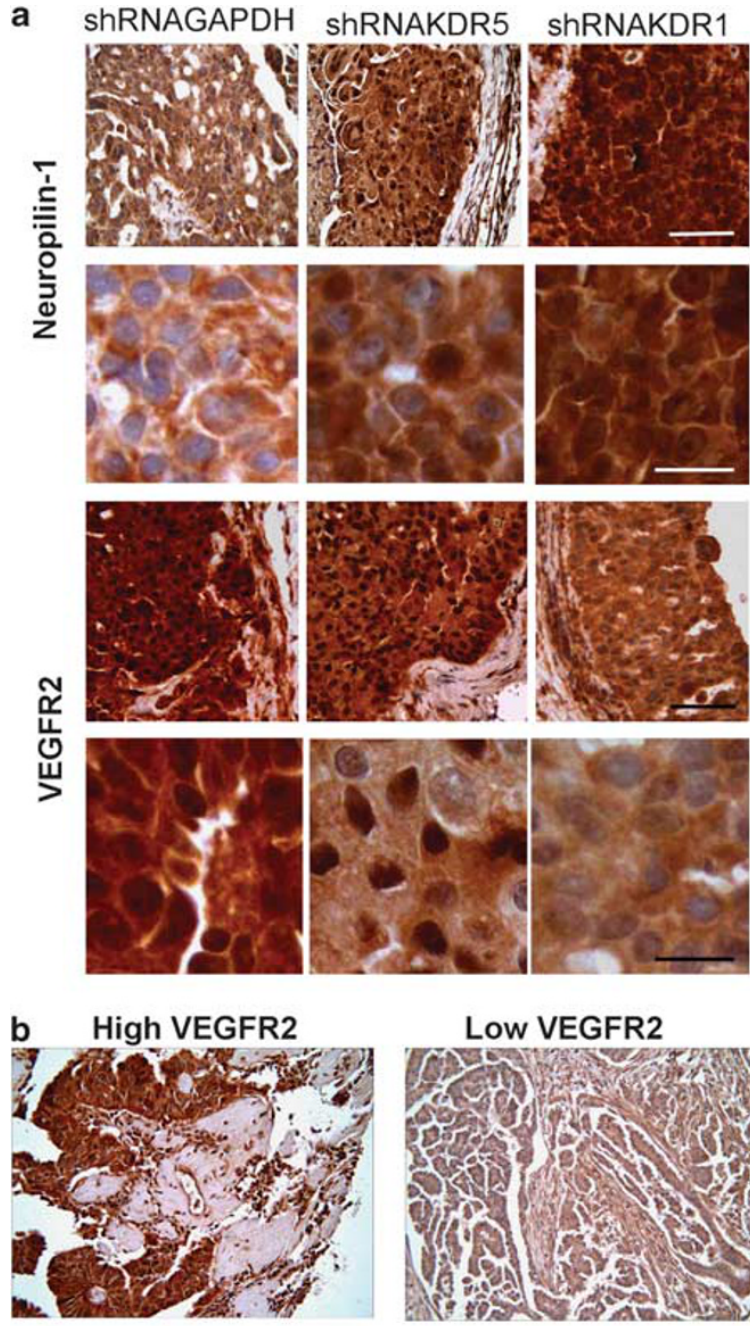

Low NRP-1
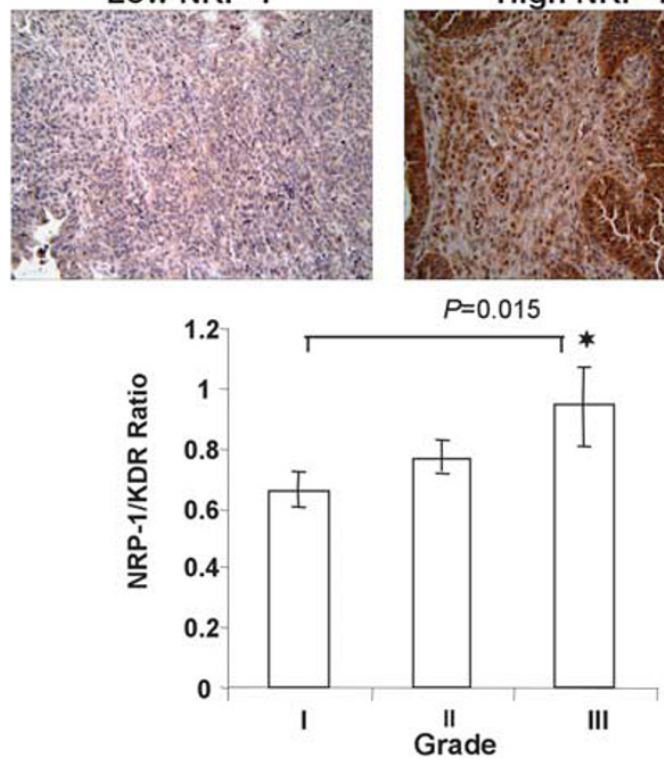

has not been well explored to date. Pharmacological blockade of VEGFR2 shows inhibitory effects on ovarian tumor growth in mice, ${ }^{27}$ and our recent studies show an important role of the VEGF/VEGFR2 autocrine loop in protecting EOC cells growing in suspension from anoikis caused by the loss of adhesion. $^{21}$ Considering that drug resistance is a common problem in EOC and other cancers in general, ${ }^{13}$ in this study we examined the effects of permanently disrupting this autocrine loop by abolishing $K D R$ expression in EOC cells.

Peritoneal ascites accumulation in ovarian carcinoma is enhanced by the production of vascular permeability agents, including VEGF. ${ }^{28}$ Cell survival under conditions of ascites accumulation in the intraperitoneal cavity may be an important contributor to disease progression in patients with EOC. Surprisingly, we found that once $K D R$ was stably knocked down in EOC cells, there was a compensatory mechanism supporting cell survival and viability, consistent with the idea that pathways facilitating EOC survival in suspension have an important role in ascites formation.

VEGF, VEGFR2, and NRP-1 drive physiological and pathological angiogenesis and their disruption may inhibit EOC growth. Treatment of mice with a VEGF-neutralizing antibody reduced subcutaneous tumor growth of SKOV-3 cells. ${ }^{7}$ Human KDR-specific antibody and/or murine VEGFR2specific antibody both significantly reduced EOC tumor growth in a mouse model. ${ }^{27}$ However, suppression of NRP-1 expression using RNAi showed a decrease in the malignant characteristics of transfected SKOV-3 cells, and a reduction in cell proliferation, indicating that persistently high expression of NRP-1 in ovarian cancer enhances proliferation, possibly through evasion of contact inhibition. ${ }^{18}$ Hence, the enhanced tumorigenicity observed in our VEGFR2 knockdown cells is possibly related to the greatly increased NRP-1 expression, rather than loss of VEGFR2 signaling per se.

NRP-1 is a $130-\mathrm{kDa}$ transmembrane receptor for semaphorins that was first described in the developing nervous system and expressed on axons of dorsal root ganglia, sensory, and motor neurons. ${ }^{29}$ The NRP-1 extracellular domain

Figure 8 NRP-1 and VEGFR2 immunohistochemistry. (a) Tumor sections from shRNAKDR1 xenografts reveal significantly increased staining of NRP-1 and reduced VEGFR2 staining. Upper panels: Low-power (top row) and high-power (bottom row) images of EOC xenografts stained for NRP-1. Note that tissues from xenografts created from both shRNA-transfected cell lines (KDR1 and KDR5) have higher levels of NRP-1 expression when compared with control tumor, which shows slight cytoplasmic staining (scale bar: top row $20 \mu \mathrm{m}$; bottom row, $50 \mu \mathrm{m}$ ). Lower panels: low-power (top row) and high-power (bottom row) images of EOC xenografts stained for VEGFR2. Note the shift in the expression of VEGFR2 from both cytoplasmic and nuclear in control tumors, to nuclear only in KDR5 tumors to weakly cytosolic in KDR1 tumors. (Scale bar: top row $20 \mu \mathrm{m}$; bottom row, $50 \mu \mathrm{m}$ ). (b) Higher NRP-1/VEGFR2 ratio in 80 human clinical EOC biopsies. Representative tissues from human EOC tissue microarray stained with VEGFR2 or NRP-1 showing the range of expression in human tumor samples. Scale bar $=50 \mu \mathrm{m}$. Graph shows ratio of NRP-1:VEGFR2 score from 80 EOC specimens and reveals significantly increasing ratio between tumor grades I and III. 
has heparin-binding capacity, and heparin enhances the binding of semaphoring $3 \mathrm{~A}$ and $\mathrm{VEGF}_{165}$ to NRP-1. ${ }^{30} \mathrm{~A}$ soluble form of NRP-1 secreted by PC3 prostate carcinoma, heart, and placental cells can bind VEGF $_{165}$ but not VEGF $_{121} \cdot{ }^{17}$ Although the exact function of NRP-1 in cancer cells is unknown, its expression in different tumors can result in increased malignancy by stimulating angiogenesis through its activation of cell signaling through a PI3-K-dependent pathway. ${ }^{31}$ OVCAR-3 and SKOV-3 cells also express semaphorin $3 \mathrm{~A}$ (results not shown), and thus there may be alternative signaling and binding pathways involving the increased NRP-1 and VEGF expressed and VEGF by our VEGFR2 knockdown cells.

NRP-1 expression was previously detected in 105 epithelial ovarian cancer samples, and levels in carcinomas were significantly greater than in benign tumors. ${ }^{32}$ Our results are consistent with this; we also found a relationship between the ratio of expression of both NRP-1 and VEGFR2 and human tumor progression. Although NRP-1 exerts an effect as a co-receptor for VEGFR2 in tumor angiogenesis, blocking NRP-1 using a specific peptide corresponding to the NRP-1binding site on $\mathrm{VEGF}_{165}$ induced apoptosis of murine and human breast carcinoma cells, whereas a peptide directed against VEGFR2 had no effect, reflecting the multifunctional role that NRP-1 has in autocrine anti-apoptotic signaling by VEGF in tumor cells. ${ }^{33}$

Another interesting consequence of KDR knockdown in our study was the altered expression of several adhesion molecules. Epithelial-mesenchymal transition contributes to cancer cell plasticity by increasing cell invasiveness and metastatic potential, and is characterized by loss or relocalization of epithelial markers (eg, E-cadherin and $\beta$-catenin) and gain of mesenchymal markers (eg, N-cadherin and smooth muscle actin). ${ }^{34}$ Cadherins are known regulators of cell differentiation, and E-cadherin is the prime mediator of cell-cell adhesion among epithelial cells, including the oviductal, endometrial, and cervical epithelia. ${ }^{35}$ The ovarian surface epithelium (OSE) is a major target tissue for ovarian carcinoma formation and pre-neoplastic ovarian surface epithelial cells are cohesive, non-migratory, and express E-cadherin. ${ }^{36}$ In contrast to most carcinomas that lose E-cadherin expression early in progression, E-cadherin is abundant in primary differentiated EOCs but subsequently decreases during progression to metastasis. ${ }^{37}$ Thus, loss of E-cadherin expression in our VEGFR2 knockdown cells may also contribute to the increased cellular malignancy that we observe in this study. The dual role for $\mathrm{N}$ and E-cadherin and their relationship with VEGFR2 in EOC is unknown and requires further investigation.

The fact that FAK autophosphorylation on tyrosine residue 397 occurs upon its binding to integrins ${ }^{38}$ can explain the slight reduction in p-FAK observed in our shRNAKDR cells once integrins are downregulated. Integrins have a major role in tumor growth and metastasis by transducing signals between the ECM and the cell interior. Interaction between VEGFR2 and $\alpha_{\mathrm{v}} \beta_{3}$ integrin is necessary for VEGF to signal stress-activated protein kinase-2/p38 in normal endothelial cells undergoing angiogenesis. ${ }^{39}$ Expression of VEGFR2 and $\alpha_{\mathrm{v}} \beta_{3}$ was detected in endothelial cells in SKOV-3 EOC xenografts, ${ }^{40}$ but to our knowledge, this is the first report of a relationship between VEGFR2 and integrin expression in EOC cells themselves. Our shRNAKDR OVCAR-3 cells showed altered survival in suspension, which was reflected in their ability to form ascites and subcutaneous cystic tumors in vivo. The cells with the greatest VEGFR2 knockdown generated more extensive ascites and specifically colonized the ovarian surface more aggressively. As VEGFR2 knockdown was proportional to NPR-1 upregulation, it is tempting to speculate that this enhanced malignancy is due, at least in part, to NRP-1-mediated effects.

Tumorigenicity was also inversely correlated with the level of adhesion molecules expressed by each transfected clone. NRP-1 is a receptor for semaphorin 3A, VEGF-A, Galectin-1, and hepatocyte growth factor, and is required for efficient activation of c-Met-dependent pathways that promote cell invasiveness. ${ }^{29,41}$ Thus, NRP-1 may be a key molecule holding promise for effective EOC therapy. Regulatory elements for NRP-1 transcriptional control are specific and cell-type dependant. For example, in HeLa cells NRP-1 expression is controlled by SP1, AP1, and CCAAT box transcription factors, ${ }^{42}$ whereas in neurons E2F1 factor binds directly to the endogenous $N R P-1$ promoter to positively regulate its expression. ${ }^{43}$ Production of SHH ligand and pathway activity is related to NRP-1 expression, and NRP-1 knockdown leads to reduced $\mathrm{SHH}$, Gli-1, and E-cadherin production in renal carcinoma cells. ${ }^{26}$ Similarly, blockade of the SHH pathway leads to reduced expression of E-cadherin, $\beta_{1}$ integrin, and VEGF in EOC cells. ${ }^{44}$ In contrast, we found no relationship between SHH levels and NRP-1 expression, and decreased Gli-1, E-cadherin, and $\beta_{1}$ integrin (but increased VEGF) production associated with NRP-1 upregulation, suggesting a more complex relationship between these pathways in VEGFR2 knockdown EOC cells.

Overall, our findings reveal unique and unanticipated aspects of EOC cell behavior under prolonged molecular blockade of VEGF/VEGFR2 signaling in these cells. Recent pre-clinical studies show that although VEGF blockade may provide effective control of primary tumors, it can contribute to cancer progression through enhanced invasiveness and hence metastasis. ${ }^{13,14}$ RNA interference approaches are currently being tested as potential anti-angiogenic and anti-cancer strategies. ${ }^{45}$ Our findings highlight possible confounding events that may affect the usefulness of RNAi in a therapeutic setting for disrupting EOC cell survival in ascites.

Supplementary Information accompanies the paper on the Laboratory Investigation website (http://www.laboratoryinvestigation.org)

\section{ACKNOWLEDGEMENTS}

We thank Kanwal Minhas, Steven Patten, Kristen Lacombe, Mackenzie Smith Christine Hamilton, Karolina Skowronski, and Dr Siranoush Shahrzad for 
technical assistance and help in manuscript preparation. We also thank Dr Alicia Viloria-Petit for helpful advice with manuscript preparation. This study was supported by grants to BLC from the Canadian Institutes of Health Research (Grant no. MOP 81213) and the Ontario Institute for Cancer Research (Grant no. 06NOV00232). IS was a recipient of a Canadian Institutes of Health Research postdoctoral fellowship.

\section{DISCLOSURE/CONFLICT OF INTEREST}

The authors declare no conflict of interest.

1. Dinulescu DM, Ince TA, Quade BJ, et al. Role of K-ras and pten in the development of mouse models of endometriosis and endometrioid ovarian cancer. Nat Med 2005;11:63-70.

2. Look M, Chang D, Sugarbaker PH, et al. Long-term results of cytoreductive surgery for advanced and recurrent epithelial ovarian cancers and papillary serous carcinoma of the peritoneum. Int J Gynecol Cancer 2003;13:764-770.

3. Bergers $\mathrm{G}$, Hanahan D. Modes of resistance to anti-angiogenic therapy. Nat Rev Cancer 2008;8:592-603.

4. Akutagawa N, Nishikawa A, Iwasaki M, et al. Expression of vascular endothelial growth factor and E-cadherin in human ovarian cancer: association with ascites fluid accumulation and peritoneal dissemination in mouse ascites model. Jpn J Cancer Res 2002;93: 644-651.

5. Wey JS, Stoeltzing O, Ellis LM, et al. Vascular endothelial growth factor receptors: expression and function in solid tumors. Clin Adv Hematol Oncol 2004;2:37-45.

6. Heuser LS, Taylor SH, Folkman J, et al. Prevention of carcinomatosis and bloody malignant ascites in the rat by an inhibitor of angiogenesis. J Surg Res 1984;36:244-250.

7. Mesiano S, Ferrara N, Jaffe RB, et al. Role of vascular endothelial growth factor in ovarian cancer: inhibition of ascites formation by immunoneutralization. Am J Pathol 1998;153:1249-1256.

8. Bamberger ES, Perrett CW. Angiogenesis in epithelian ovarian cancer. Mol Pathol 2002;55:348-359.

9. Mabuchi $S$, Terai $Y$, Morishige $K$, et al. Maintenance treatment with bevacizumab prolongs survival in an in vivo ovarian cancer model. Clin Cancer Res 2008;14:7781-7789.

10. Garcia AA, Hirte H, Fleming G, et al. Phase II clinical trial of bevacizumab and low-dose metronomic oral cyclophosphamide in recurrent ovarian cancer: a trial of the California, Chicago, and Princess Margaret Hospital phase II consortia. J Clin Oncol 2008;26: $76-82$.

11. Cannistra SA, Matulonis UA, Penson RT, et al. Phase II study of bevacizumab in patients with platinum-resistant ovarian cancer or peritoneal serous cancer. J Clin Oncol 2007;25:5180-5186.

12. Han ES, Lin P, Wakabayashi M. Current status on biologic therapies in the treatment of epithelial ovarian cancer. Curr Treat Options Oncol 2009;10:54-66.

13. Ebos JM, Lee CR, Cruz-Munoz W, et al. Accelerated metastasis after short-term treatment with a potent inhibitor of tumor angiogenesis. Cancer Cell 2009;15:232-239.

14. Paez-Ribes $M$, Allen $E$, Hudock J, et al. Antiangiogenic therapy elicits malignant progression of tumors to increased local invasion and distant metastasis. Cancer Cell 2009;15:220-231.

15. Loges $S$, Mazzone $M$, Hohensinner $P$, et al. Silencing or fueling metastasis with VEGF inhibitors: antiangiogenesis revisited. Cancer Cell 2009:15:167-170.

16. Kim KJ, Li B, Winer J, et al. Inhibition of vascular endothelial growth factor-induced angiogenesis suppresses tumour growth in vivo. Nature 1993;362:841-844.

17. Soker S, Takashima S, Miao HQ, et al. Neuropilin-1 is expressed by endothelial and tumor cells as an isoform-specific receptor for vascular endothelial growth factor. Cell 1998;92:735-745.

18. Baba $T$, Kariya $M$, Higuchi $T$, et al. Neuropilin-1 promotes unlimited growth of ovarian cancer by evading contact inhibition. Gynecol Oncol 2007;105:703-711.

19. Stoeck $A$, Schlich S, Issa $Y$, et al. L1 on ovarian carcinoma cells is a binding partner for neuropilin-1 on mesothelial cells. Cancer Lett 2006;239:212-226.
20. Zhang L, Conejo-Garcia JR, Yang N, et al. Different effects of glucose starvation on expression and stability of VEGF mRNA isoforms in murine ovarian cancer cells. Biochem Biophys Res Commun 2002;292:860-868.

21. Sher I, Adham SA, Petrik J, et al. Autocrine VEGF-A/KDR loop protects epithelial ovarian carcinoma cells from anoikis. Int J Cancer 2009;124:553-561.

22. Murga M, Fernandez-Capetillo O, Tosato G, et al. Neuropilin-1 regulates attachment in human endothelial cells independently of vascular endothelial growth factor receptor-2. Blood 2005; 105:1992-1999.

23. Fiedler J, Leucht F, Waltenberger J, et al. VEGF-A and PIGF-1 stimulate chemotactic migration of human mesenchymal progenitor cells. Biochem Biophys Res Commun 2005;334:561-568.

24. Mombaerts P, lacomini J, Johnson RS, et al. RAG-1-deficient mice have no mature B and T lymphocytes. Cell 1992;68: 869-877.

25. Kou R, SenBanerjee $S$, Jain $M K$, et al. Differential regulation of vascular endothelial growth factor receptors (VEGFR) revealed by RNA interference: interactions of VEGFR-1 and VEGFR-2 in endothelial cell signaling. Biochemistry 2005;44:15064-15073.

26. Cao Y, Wang L, Nandy D, et al. Neuropilin-1 upholds dedifferentiation and propagation phenotypes of renal cell carcinoma cells by activating akt and sonic hedgehog axes. Cancer Res 2008;68: 8667-8672.

27. Spannuth WA, Nick AM, Jennings NB, et al. Functional significance of VEGFR-2 on ovarian cancer cells. Int J Cancer 2008;124: 1045-1053.

28. Nagy JA, Masse EM, Herzberg KT, et al. Pathogenesis of ascites tumor growth: vascular permeability factor, vascular hyperpermeability, and ascites fluid accumulation. Cancer Res 1995;55:360-368.

29. He Z, Tessier-Lavigne M. Neuropilin is a receptor for the axonal chemorepellent semaphorin III. Cell 1997;90:739-751.

30. De Wit J, De Winter F, Klooster J, et al. Semaphorin 3A displays a punctate distribution on the surface of neuronal cells and interacts with proteoglycans in the extracellular matrix. Mol Cell Neurosci 2005;29:40-55.

31. Neufeld G, Kessler $O$. The semaphorins: versatile regulators of tumour progression and tumour angiogenesis. Nat Rev Cancer 2008;8:632-645.

32. Osada R, Horiuchi A, Kikuchi N, et al. Expression of semaphorins, vascular endothelial growth factor, and their common receptor neuropilins and alleic loss of semaphorin locus in epithelial ovarian neoplasms: increased ratio of vascular endothelial growth factor to semaphorin is a poor prognostic factor in ovarian carcinomas. Hum Pathol 2006;37:1414-1425.

33. Barr MP, Byrne AM, Duffy AM, et al. A peptide corresponding to the neuropilin-1-binding site on $\operatorname{VEGF}(165)$ induces apoptosis of neuropilin-1-expressing breast tumour cells. Br J Cancer 2005;92: 328-333.

34. De Wever O, Pauwels P, De Craene B, et al. Molecular and pathological signatures of epithelial-mesenchymal transitions at the cancer invasion front. Histochem Cell Biol 2008;130:481-494.

35. Wong AS, Maines-Bandiera SL, Rosen B, et al. Constitutive and conditional cadherin expression in cultured human ovarian surface epithelium: influence of family history of ovarian cancer. Int J Cancer 1999;81:180-188.

36. Sundfeldt K. Cell-cell adhesion in the normal ovary and ovarian tumors of epithelial origin; an exception to the rule. Mol Cell Endocrinol 2003:202:89-96.

37. Imai T, Horiuchi A, Shiozawa $\mathrm{T}$, et al. Elevated expression of E-cadherin and alpha-, beta-, and gamma-catenins in metastatic lesions compared with primary epithelial ovarian carcinomas. Hum Pathol 2004;35: 1469-1476.

38. Schaller MD, Hildebrand JD, Shannon JD, et al. Autophosphorylation of the focal adhesion kinase, pp125FAK, directs SH2-dependent binding of pp60src. Mol Cell Biol 1994;14:1680-1688.

39. Masson-Gadais B, Houle F, Laferriere J, et al. Integrin alphavbeta3, requirement for VEGFR2-mediated activation of SAPK2/p38 and for Hsp90-dependent phosphorylation of focal adhesion kinase in endothelial cells activated by VEGF. Cell Stress Chaperones 2003;8: 37-52. 
40. Willmann JK, Lutz AM, Paulmurugan R, et al. Dual-targeted contrast agent for US assessment of tumor angiogenesis in vivo. Radiology 2008;248:936-944.

41. Matsushita A, Gotze T, Korc M. Hepatocyte growth factor-mediated cell invasion in pancreatic cancer cells is dependent on neuropilin-1. Cancer Res 2007;67:10309-10316.

42. Rossignol M, Pouyssegur J, Klagsbrun $M$, et al. Characterization of the neuropilin-1 promoter; gene expression is mediated by the transcription factor Sp1. J Cell Biochem 2003;88:744-757.
43. Jiang SX, Sheldrick M, Desbois A, et al. Neuropilin-1 is a direct target of the transcription factor E2F1 during cerebral ischemia-induced neuronal death in vivo. Mol Cell Biol 2007; 27:1696-1705.

44. Liao X, Siu MK, Au CW, et al. Aberrant activation of hedgehog signaling pathway in ovarian cancers: effect on prognosis, cell invasion and differentiation. Carcinogenesis 2009;30:131-140.

45. Castanotto D, Rossi JJ. The promises and pitfalls of RNA-interferencebased therapeutics. Nature 2009:457:426-433. 